More extensive experiments were then carried out, using as a criterion the difference in L.D.50 determined by the probit method for control and alcoholtreated mice. For this determination four or five dose-levels were chosen which could be presumed to bracket the 50 per cent lethal dose for this strain of mice. One group of alcohol-treated and one group of control mice were irradiated at each dose-level.

The figures obtained in one experiment are shown in Table 2; they demonstrate a rise in the L.D.50 dose with alcohol treatment $(1.5 \mathrm{ml}$. 10 per cent alcohol, given as two doses before irradiation). Table 2

$$
\begin{array}{cccc} 
& \text { Number of mice } & \text { T.D.50 } & \text { Stand. dev. of L.D.50 } \\
\text { ex-1cohol } & 110 & 625 \mathrm{r} . & 13.3 \mathrm{r} . \\
\text { Saline } & 109 & 554 \mathrm{r} . & 8.7 \mathrm{r} .
\end{array}
$$

The difference here is highly significant $\left(p>10^{-4}\right)$.

The protective effect of alcohol was also examined from the point of view of the lengthening of the time of survival of mice which die within the time-span of the experiment (thirty days).

It has been found from other experiments that at doses at and above the L.D.100 level the mean survival-time of mice decreases inversely with dose. The mean survival-time was calculated for two experiments. In one, mice were irradiated with $690 \mathrm{r}$., in the second with $700 \mathrm{r}$. In the first experiment the mean survival-time for saline-treated controls was $10 \cdot 0$ days, that for alcohol-treated animals being 12.5 days. In the second experiment the figure for controls was $9 \cdot 0$ days, compared with $12 \cdot 1$ days for alcohol-treated mice. The difference in both cases is significant $(p=0.05)$.

It would therefore seem that the administration of alcohol prior to radiation increased the dose required to kill 50 per cent of the mice, and extended the life of non-survivors.

No protection was obtained when the 10 per cent alcohol solution was given after radiation in two doses, $1 \mathrm{ml}$. immediately after radiation followed by $0.5 \mathrm{ml}$. one hour thereafter.

Comparison of the protective effects of equal volumes of 10 per cent or 5 per cent alcohol showed that both concentrations were protective, but that the difference in protection value between them was not significant.

In an attempt to compare the protective effect of alcohol with that of cysteine, using the same strain of mice, it was found that an intravenous dose of $20 \mathrm{mgm}$. cysteine per mouse seemed to have a rather greater effect than oral alcohol in the doses used. We have not tried the effects of higher doses of alcohol.

The protective effect of alcohol is probably unrelated to its anæsthetic effect. Although the majority of mice given $1.5 \mathrm{ml}$. of 10 per cent alcohol were rendered unconscious, this was rarely the case for mice given the same volume of 5 per cent alcohol.

Furthermore, we have tested two other substances at anæsthetic doses for protection: (a) nembutal intravenously, 1.3 mgm. per mouse, $(b)$ ethyl carbamate intraperitoneally, $20 \mathrm{mgm}$. per mouse. Neither of these substances altered the L.D.50. This was rather surprising in the case of ethyl carbamate, as this has been found to lessen the lethal effect of $\mathrm{X}$-rays on cells in vitro.

Department of Radiobiology,

Edith Paterson

Joyce J. Matrhews

Christie Hospital and Holt Radium Institute, Manchester 20.

Aug. 10

\section{Microspheres of Organic Substances}

SphERICAL particles of glass ranging in diameter from about one micron upwards, which can be prepared by the method of Bloomquist and Clark ${ }^{1}$, have found a wide range of usefulness, for example, as adsorbents of known surface area ${ }^{2}$, as material for the study of 'fluidization' of beds of particles ${ }^{3}$, and in electrokinetic measurements on cataphoresis and sedimentation velocity ${ }^{4,5}$. For many such experiments, particularly the electrokinetic ones, it would be desirable to be able to use microspheres of substances other than glass. I have found that it is possible to obtain many organic compounds in microspherical form, provided that they melt below $100^{\circ} \mathrm{C}$., and are more or less insoluble in water. The sub. stance to be used is mechanically stirred at a very high rate with thirty to forty times its weight of water, at a temperature $10-15^{\circ}$ above the melting point of the substance, thus producing an unstable emulsion of liquid drops in water. This is then run rapidly into a large excess of cold water, producing solid spherical particles of the substance. Some degree of control over the size of particle obtained can be exercised by modifying the rate and time of stirring. In this way, microspheres of naphthalene, octadecane, $m$-dinitrobenzene, cetyl alcohol, stearin, stearic acid, and several other organic compounds have been prepared. These particles are used in the study of the electrokinetic properties of organic compounds by the method of electroviscous sedimentation ${ }^{6}$.

Most of these particles keep indefinitely under water, but if allowed to dry off, some of the softer ones tend to lose their shape. Some aggregation may also occur on drying, and the particles are then difficult to redisperse, so that it is advisable to store them under water so far as possible.

It should prove feasible to apply this method to low-melting inorganic substances, using non-aqueous liquids as dispersing media.

Chemistry Department,

Battersea Polytechnic,

London, S.W.11. Aug. 3.

${ }^{1}$ Bloomquist, C. R., and Clark, A., Indust. Eng. Chem. (Anal. Edit.), 12, 61 (1940).

${ }^{2}$ Urbanic, A. J., and Damerell, V. R., J. Phys. Chem., 45, 1245 (1941).

${ }^{3}$ Lewis, W. K., Gilliland, E. R., and Bauer, W. C., Indust. Eng. Chem., 41, 1104 (1949).

Hirschler, F. G., Ph.D. Thesis, University of London (1951).

${ }^{5}$ Elton, G. A. H., and Hirschler, F. G. (to be published shortly).

${ }^{6}$ Elton, G. A. H., Proc. Roy. Soc., A, 197, 568 (1949).

\section{An Isopod, Asellus meridianus Racovitza, with Low Chromosome Number}

IN the past fifty years, several papers have described the chromosomes of Isopoda, and the numbers for twenty-seven species have been recorded. Most of this work has been done by Vandel ${ }^{1,2}$. The numbers range from 6 to 60 taking the group as a whole, but some families may show less variation than others $^{5}$ :

Haploid

numbers :

Flabellifera

Epicoridea

Asellota

Oniscoidea

$6,7,8-16,17-24-27,28,29,30,31-34-60$

$\begin{array}{llllll} & 1 & & & & \\ 1 & 3 & & & & 1 \\ & 3 & 1 & 1 & 2 & \end{array}$

26

11 